\title{
A gestão pedagógica face "ao termômetro" da qualidade educacional: o ideb como modelador de práticas educacionais
}

\section{Pedagogic management in the face of the "termometer" of educational quality: the ideb as a model for educational practices}

DOI: $10.46814 / \operatorname{lajdv3n4-028}$

Recebimento dos originais: 01/05/2021

Aceitação para publicação: 31/06/2021

\section{Simone da Costa Silva}

Doutoranda em Educação - PPGE/CEDU/UFAL

Instituição: Universidade Federal de Alagoas (UFAL)

Endereço: Universitário A. C. Simões - BR 104, Km 97,6, s/n - Tabuleiro do Martins, Maceió - AL. 57072-970

E-mail: simonecostaufal@gmail.com

\section{Elione Maria Nogueira Diógenes}

Pós-Doutorado na área de Políticas Públicas da Educação

Professora Associada I da Universidade Federal de Alagoas (UFAL)

Endereço: Universitário A. C. Simões - BR 104, Km 97,6, s/n - Tabuleiro do Martins, Maceió - AL. 57072-970

E-mail: elionend@uol.com.br

\author{
Maria Cledilma Ferreira da Silva Costa \\ Doutoranda em Educação - PPGE/CEDU/UFAL \\ Instituição: Universidade Federal de Alagoas (UFAL) \\ Endereço: Universitário A. C. Simões - BR 104, Km 97,6, s/n - Tabuleiro do Martins, Maceió - AL. \\ 57072-970 \\ E-mail: cledilma.costa@ifal.edu.br
}

\section{RESUMO}

Este trabalho apresenta um recorte dos resultados de uma pesquisa de mestrado que buscou analisar como o IDEB vem interferindo na gestão pedagógica escolar, visto que, esse índice, como um instrumento de controle da qualidade educacional, pode torna-se um modelador de práticas educativas. Na busca por compreender a problemática elencada, tomou-se uma metodologia comparativa com base nas orientações qualitativas de pesquisa, analisando-se duas escolas, uma com indicador elevado e outra com o índice baixo. Além da observação nessas instituições, realizou-se entrevistas com coordenadores e professores, em que suas falas foram analisadas com base na técnica de análise do conteúdo. Os dados levantados confirmam que o IDEB, em formatos diferentes, vem modelando as ações dessas escolas.

Palavras-chave: Gestão pedagógica, Índice de Desenvolvimento da Educação Básica, políticas educacionais.

\section{ABSTRACT}

This paper presents a section of the results of a master's research that sought to analyze how the IDEB has been interfering in school educational management, since this index, as an instrument of educational quality control, can become a modeler of educational practices. In the search for an 
understanding of the listed problem, a comparative methodology was used based on qualitative research guidelines, analyzing two schools, one with a high indicator and the other with a low index. In addition to the observation in these institutions, interviews were held with coordinators and teachers, in which their statements were analyzed based on the content analysis technique. The data collected confirm that the IDEB, in different formats, has been shaping the actions of these schools.

Keywords: Pedagogical management, Basic Education Development Index, educational policies.

\section{INTRODUÇÃO}

A partir da década de 1990 com o capitalismo monopolista internacional e nacional, o Estado vem sofrendo redefinições em seu papel para atender o novo projeto de sociedade burguesa que passa requerer um novo tipo de homem e trabalhador. Segundo Neves (2005) o Estado vem intensificando com todos os instrumentos legais e ideológicos, o seu papel de educador, ou seja, de instrumento de confirmação cognitiva e comportamental do brasileiro ao projeto de sociabilidade burguesa, de modo que programa posturas e práticas condizentes com a lógica capitalista.

O Estado passa a cumprir novas competências e funções, não mais como promotor direto do crescimento econômico, mas como catalisador e facilitador do mesmo (PECI, 1999, p.255). Em tal sentido, passa desenvolver práticas como a responsabilidade social, que impõe a sociedade civil o papel de executor de políticas sociais.

No campo educacional, conforme Ferreira (2009), as reformas empreendidas na década de 1990 estão voltadas para uma ação descentralizadora, de controle e de privatização. A partir desta política a instituição educacional e seus profissionais assumem maiores responsabilidades diante dos resultados educacionais.

Diante dessa descentralização, o Estado difunde o argumento de que se faz necessário à criação de políticas educacionais do controle dos resultados, nisto a implantação de avaliações em larga escala é uma das medidas adotadas para a mensuração dos resultados educacionais.

Nesse novo modelo a comunidade escolar (gestores, professores e alunos) é a responsável pelo êxito ou fracasso, e o Estado isenta-se de suas responsabilidades. De acordo com Sousa (2008), há um deslocamento das discussões da qualidade no âmbito político/público para o âmbito técnico/individual.

Dentro desse cenário, em 2007 o governo brasileiro criou o Plano de Desenvolvimento Educacional (PDE), composto por quarenta programas voltados para a educação. Dentre estes programas, encontra-se à promulgação do Índice de Desenvolvimento da Educação Básica (IDEB) como instrumento para aferir a qualidade da educação brasileira. O IDEB tem por objetivo fazer um levantamento de cada escola e de cada rede de ensino que apresentam um baixo desempenho escolar e consequentemente precisam de maior apoio financeiro e de gestão. 
O IDEB surge como um indicador dos problemas educacionais brasileiros e direciona as políticas educacionais com o intuito de melhorar a qualidade do ensino público brasileiro.

O índice das escolas é medido a cada dois anos. E para que as instituições escolares obtenham uma boa média é necessário que seus alunos tenham êxito na Prova Brasil, que avaliam os aluno dos $5^{\circ}$ e $9^{\circ}$ anos e da $3^{\text {a }}$ série do ensino médio nas áreas de Língua Portuguesa e Matemática, como também é necessário que os discentes sejam aprovados no ano letivo que estão cursando. A meta é que o Brasil atinja nota 6 até 2022, para isto estados e municípios devem traçar metas para atingi-la.

Dentro desse cenário de avaliações em larga escala como o IDEB, Afonso (2001) afirma que a autonomia das escolas é ameaçada pelo aumento da interferência e do controle estatal sobre as políticas curriculares e de gestão dos professores que é influenciada pela lógica competitiva e individualista.

Nesta perspectiva, para concretizar esse novo projeto, o Estado interfere nas instituições sociais, assumindo, assim, uma postura intervencionista. Essa interferência do Estado, conforme Afonso (2001) ocorre, acima de tudo, através da promoção de um ethos competitivo que nesse momento começa se torna mais explícito quando se observam, por exemplo, as pressões exercidas sobre as escolas a partir de uma racionalidade excessivamente instrumental e mercantil que dão grande relevância aos resultados quantitativos, sem levar em consideração as especificidades do contexto escolar e dos processos de aprendizagens.

Este fato pode ser comprovado a partir da análise de que os processos de avaliação estão ligados intimamente às finalidades pelo fato de que a avaliação é quem valida os conteúdos, ela atua como uma pressão modeladora da prática curricular, ligada a outros agentes, como a política curricular, o tipo de tarefas nas quais se expressa o currículo e o professorado escolhendo conteúdos ou planejando atividades [...] SACRISTÁN (2000, p. 311), ou seja, a avaliação tem a sua centralidade no ato pedagógico, pois ela é que definirá o que deve ser estudado.

Com base nisto, o presente trabalho, resultante de uma pesquisa desenvolvida durante o processo de mestrado acadêmico no Programa de Pós-graduação em Educação da Universidade Federal de Alagoas, na linha de História e Política, se debruçou na busca por resposta do seguinte questionamento: Como o vem interferindo na gestão pedagógica escolar?

Considerando a problemática levantada, esta pesquisa objetivou analisar como a gestão pedagógica e os professores vêm articulando a sua prática pedagógica com as habilidades (descritores) exigidas no IDEB, buscando compreender quais as metamorfoses que ocorrem ou não na sala de aula. Neste sentido, com a pretensão de atingir o objetivo elencado, tomou-se o método comparativo como caminho a ser seguido dentro de uma vertente qualitativa, por analisar duas escolas públicas estaduais com condições semelhantes e resultados díspares no Índice de Desenvolvimento da Educação Básica. Sendo assim, esse trabalho inicialmente realiza uma análise do surgimento do IDEB como instrumento 
de avaliação da qualidade educacional dentro do Plano de Desenvolvimento da Educação (PDE) e seu Plano de Metas Compromisso Todos pela Educação, em seguida, será abordado a gestão pedagógica em face desse indicador.

\section{A IMPLANTAÇÃO DO IDEB COMO UM “TERMÔMETRO" DA QUALIDADE EDUCACIONAL BRASILEIRA}

Para a compreensão de como se configura o Índice de Desenvolvimento da Educação Básica se faz necessário uma análise do Plano de Desenvolvimento da Educação (PDE) e seu Plano de Metas Compromisso Todos pela Educação que o legitima como um "termômetro" da qualidade educacional brasileira.

O primeiro momento em que foi ratificado o interesse em criar um Plano de Desenvolvimento para Educação aconteceu quando o então ex presidente Luís Inácio Lula da Silva lança, em janeiro de 2007, cria o Programa de Aceleração do Crescimento (PAC), um plano que agrega diversas políticas econômicas com a finalidade de acelerar o crescimento econômico do país. Sobre esse prisma, o Ministério da Educação também lança o PDE, que diferentemente do Plano Nacional de Educação (PNE) que se configura como uma política de Estado, esse plano foi promulgado como uma política de governo, visando "superar algumas dificuldades do PNE em torno de uma questão central: o tratamento dado à qualidade" (BRASIL, 2008, p.21).

Saviani ao traçar uma análise crítica do PDE afirma que da forma como este plano está configurado "não traz garantias de que as medidas propostas surtirão o efeito pretendido e esperado", pois de acordo com esse autor a maneira como foi proposto ele está passível de manipulações por parte dos municípios para garantir o recebimento de recursos. (SAVIANI, 2007, p.1232).

Esse plano, o PDE, está estruturado em torno de uma visão sistêmica de educação, que segundo um documento apresentado pelo MEC em 2008, se trata de "uma concepção substantiva de educação que perpassa todos os níveis e modalidades educacionais", ou seja, nesta perspectiva os níveis e modalidades de educação são encarados como momentos de um mesmo processo (BRASIL, 2008, p.7). Desse modo, afirmando atender a essa concepção, o plano foi dividido em quatro eixos: educação básica, educação superior educação profissional e alfabetização, estruturado em mais de 40 programas.

Apesar de o plano defender a visão sistêmica de educação, Saviani (2007) alerta para o fato de que os programas expostos no PDE estão apresentados como um "aglomerado de ações" com perfis e objetivos totalmente diferentes entre si, não havendo articulação entre eles.

Nessa direção Camini (2009) afirma que tais programas possuem um "caráter provisório", sendo, assim, estão constantemente sendo alterados, em que este fato pode ser comprovado pelo aumento expressivo do número de programas e ações, pois quando foi cogitada a intenção de se criar 
um plano de desenvolvimento esse estava estruturado em 20 ações, mas no mês de novembro de 2009, em pouco tempo de sua promulgação, o plano já contava com 208 ações. Cumpre observar que na verdade o PDE "aparece como um grande guarda-chuva que abriga praticamente todos os programas em desenvolvimento pelo MEC”. (SAVIANI, 2007, p.1233).

A partir de um documento exposto pelo MEC no ano seguinte á promulgação do PDE, com autoria do então ministro da educação que explicita os princípios desse plano, é possível perceber que os pressuposto e finalidades que embasam essa política quando é afirmado o seguinte:

Dois imperativos se desdobram dos propósitos do Plano: responsabilização (o que se conhece na literatura como accountability) e mobilização social. Se a educação é definida, constitucionalmente, como direito de todos e dever do Estado e da família, exige-se considerar necessariamente a responsabilização, sobretudo da classe política, e a mobilização da sociedade como dimensões indispensáveis de um plano de desenvolvimento da educação. Com efeito, a sociedade somente se mobilizará em defesa da educação se a incorporar como valor social, o que exige transparência no tratamento das questões educacionais e no debate em torno das políticas de desenvolvimento da educação. Desse modo, a sociedade poderá acompanhar sua execução, propor ajustes e fiscalizar o cumprimento dos deveres do Estado. (BRASIL, 2007, p.11)

Com base na citação acima e na de outro documento que é afirmado que o MEC pretende mostrar à sociedade tudo o que se passa adentro e fora da escola, é possível vislumbrar o fato de que nesse plano educacional, o PDE, há uma forte defesa de modelos de prestação de contas por parte da escola à sociedade que legitimam a ideologia de mercado no campo educacional, em nesta perspectiva a instituição escolar passa a ser encarada como mercadoria, por isso os seus resultados devem ser aferidos para demonstrar em que medida os recursos aplicados rederam resultados favoráveis esperados.

Diante disso, gestores e professores serão considerados os grandes responsáveis pelo produto (resultado) apresentado pela escola pelo fato de que essa prestação de contas será acompanhada por toda sociedade, que assim como um consumidor, passará a exigir da escola a apresentação de melhores resultados.

As fortes pressões exercidas aos educadores podem ser até mesmo notadas nos discurso presentes em alguns documentos oficiais do governo federal que atribuem os resultados escolares não as condições materiais da escola e a origem social dos alunos, mas a prática desenvolvida nas escolas. Um exemplo bem enfático de tal argumento estar presente em documento lançado em 2009, que após realizar uma análise dos dados da Prova Brasil, levando em consideração as diferenças, afirma que "a diferença entre escolas de uma mesma linha não está nos alunos esta deve ser procurada na gestão pedagógica, na forma de ensinar, na cultura ou nos valores da escola ou no projeto pedagógico". (BRASIL, 2009, p.10). Desse modo, “essa avaliação pode funcionar como um elemento de pressão, 
para pais e responsáveis, por melhoria da qualidade da educação de seus filhos, uma vez que, a partir da divulgação dos resultados, eles podem cobrar providências para que a escola melhore." (BONAMINO; SOUSA, 2012 P.379).

No que concerne a Educação Básica, inicialmente o plano estava estruturado em 17 ações, dentre as quais para o acompanhamento dos objetivos propostos nos programas do PDE voltados à Educação Básica foi criado o Índice de Desenvolvimento da Educação Básica (IDEB), que "pretende ser o termômetro da qualidade da educação básica em todos estados, municípios e escolas do Brasil”" (BRASIL, 2009, p.4).

Com base nisto, o IDEB surge o com pressuposto de verificar a qualidade da educação básica brasileira, sendo, assim para que uma escola venha a ser considerada como uma instituição de qualidade se faz necessário que ela obtenha uma boa média nesse instrumento. No entanto, avaliação das condições da educação no Brasil na forma como ela vem sendo apresentada ainda é muito limitada, pois seria "necessário observar outros conceitos, como políticas pedagógicas, currículo, formação, saúde, e carreira dos profissionais, infraestrutura e violência nas escolas, relação professor, relação profissionais/alunos, e, fundamentalmente a gestão democrática”. (CAMINI, 2009, p. 170).

Assim, o PDE atribui às avaliações externas uma grande importância na condução da educação brasileira, promovendo, “inclusive, inéditas conexões entre avaliação, financiamento e gestão, que invocam conceito até agora ausente do nosso sistema educacional: a responsabilização e, como decorrência, a mobilização social. (BRASIL, 2007, p.19)", o que se nota a partir disso é uma forte associação dos resultados nesses exames para a alocação e gestão de recursos, pois o MEC tomará os resultados desse índice para identificar quais escolas necessitam de um maior apoio técnico e financeiro. .

Os indicadores do IDEB são construídos desconsiderando as avaliações internas das escolas, desconsiderando também a necessidade de uma pesquisa in lócus e quando o MEC realiza pesquisas dentro das instituições, essa é feita com o intuito de apresentar escolas, que mesmo sem as condições objetivas obtiveram uma boa média, apresentando-as como modelo, em que um exemplo marcante disso é o estudo desenvolvido em 2007 pela UNICEF o Aprova Brasil, em 33 escolas de 14 estados brasileiros, procurando identificar as práticas de ensino-aprendizagem dessas escolas que a levaram obter um bom indicador.

Cabe atentar, que esse tipo de pesquisa "pode passar a ideia de que o problema é de gestão e de falta de empenho de professores, desconsiderando todas as variáveis que envolvem o processo de ensino-aprendizagem nas escolas, em especial a necessidade de mais recursos para a educação" (CAMINI, 2009, p. 141). Sob esse prisma, é necessário levantar como a gestão pedagógica vem se 
articulado para obter uma boa média, já que o problema da qualidade educacional foi transferido para esse âmbito educacional.

\section{A GESTÃo PEDAGÓGICA DIANTE DO IDEB}

Para uma compreensão do que é a gestão pedagógica convém resgatar o sentido do que é pedagogia, que é "um ramo da ciência direcionado à compreensão de uma prática social e complexa que é a educação" (ALMEIDA; SOARES, 2010, p.15). Neste sentido, o trabalho pedagógico consiste "em um conjunto de práticas sociais intencionalmente sistematizadas de formação humana, que ocorre nas relações sociais de acordo com cada fase específica de desenvolvimento das forças produtivas" (ibidem, p.16).

Nesta perspectiva, o trabalho pedagógico constitui um campo estratégico de disseminação de novas ideologias, pois esse profissional surgiu justamente da transposição de novas estratégias econômicas de administração, em que:

No âmbito da administração empresarial, à luz da própria concepção taylorista de management, desenvolveram-se novos conceitos administrativos, como os de gestão e gerência, que rapidamente invadiram as distintas áreas temáticas da administração. Surgiram, assim, os cargos de gestor e gerente, em substituição ou adição aos de administrador e diretor. (SANDER, 2005, p.44, grifo do autor).

No campo educacional, há o surgimento do supervisor pedagógico dentro de um contexto de separação entre o pensar e o executar, instaurado um controle semelhante ao que é vivenciado nas fábricas em busca da eficiência. A presença desse profissional nas escolas garante a divisão do trabalho "entre aqueles que definem, acompanham e controlam o processo de ensino (os supervisores) e aqueles que desenvolvem as atividades docentes (os professores)" (ALMEIDA; SOARES, 2010, p.21). De um modo, geral esse administrador escolar passa a ser encarado como um simples executor do que foi deliberado em instâncias superiores.

Todavia, é relevante ressaltar a necessidade de se superar essa visão fragmentada do trabalho pedagógico, pois “os professores como profissionais da educação têm no pedagógico a centralidade de seu trabalho e dentro da sala de aula são os gestores do pedagógico.” (MACÊDO, 2011, p.84).

No cenário da década de 1980 e 1990, de Reforma das Políticas Educacionais, o termo administração escolar é substituído pelo termo gestão, que Falsarella (2014, p.1) a partir de Luck expõe "que não se trata da simples troca de um termo pelo outro, porém da proposição de um novo conceito de organização educacional".

Para Sander (2005, p.47) argumenta que "a gestão da educação abarca desde a formulação de políticas, planos institucionais e a concepção de projetos pedagógicos para os sistemas educacionais e 
as instituições escolares até a execução" Com base nisto, a gestão pedagógica para alguns autores se configura como um dos ofícios da gestão educacional e escolar e de acordo com Hengemuhle, (2004, p.191) a gestão pedagógica é o âmbito mais importante da gestão educacional, pois o gestor será um líder responsável pela coordenação do projeto pedagógico da instituição.

Neste sentido, de acordo com Ferreira (2013, p. 113) a gestão pedagógica:

\begin{abstract}
A gestão do pedagógico é mais do que o planejamento, a elaboração do Projeto Pedagógico da instituição. Incluem todas as práticas pedagógicas, as crenças, os estudos, os planejamentos, enfim, todas as ações que resultam na atividade central da escola: a aula e na atividade básica dos professores: a produção do conhecimento sua e dos estudantes. Não é, portanto, atividade individual. Ao contrário, é coletiva, pois exige diálogo, participação, implicação, atitude, comprometimento, ação. Essas exigências contribuem para que os professores estejam em processos de referência e auto-referência, entendendo-se como coletividade, porque uma ação implicará nas ações dos outros e isso vale até mesmo para as resistências, serão sempre implicadas nas resistências dos demais integrantes da escola.
\end{abstract}

Esta dimensão da gestão educacional está voltada para o objetivo primordial da escola que é o processo de ensino-aprendizagem, em que todas as demais dimensões da gestão educacional devem estar voltadas para ela e o papel do gestor é acompanhar as ações que estão diretamente relacionadas ao planejamento, ao ensino e a sala de aula.

$\mathrm{Na}$ atualidade, a gestão pedagógica educacional vem sendo pressionada pelas políticas de avaliações na busca de melhores resultados no Índice de Desenvolvimento da Educação Básica (IDEB). Com base nisto, professores e gestores têm voltado suas práticas, mesmo que parcialmente, para as orientações propostas nestas avaliações padronizadas pelo fato de esse instrumento consolida um processo de responsalização desses educadores mediante a divulgação de ranking das escolas, privilegiando uma pedagogia de resultados, em que "o governo se equipa com os instrumentos de avaliação dos produtos, forçando, com isso, que o processo se ajuste às exigências postas pela demanda das empresas". (SAVIANI, 2007, p. 1253).

Com base nisso, primeiro momento da entrevista com gestores e professores das duas escolas investigada se ateve ao interesse levantar a visão desses educadores sobre IDEB, enquanto política avaliativa da qualidade educacional. Nessa oportunidade os sujeitos entrevistados fizeram uso de suas falas para apontar da maneira como o IDEB é visto pela equipe escolar:

Ele não mudam nada! Ficam camuflando uma realidade, entendeu? Porque eu digo isso, porque quando chega o final, tem crianças que... aqui mesmo tem um quinto ano eu tenho uma quando você pede ao menino leia e o menino e você percebe a dificuldade que eles tem para ler, né? [...] mas eu não sei (risos) às vezes eu fico na dúvida com relação ao IDEB, porque me surpreendi, em 2009 eu me surpreendi com a nota porque foi superior a 2007, e 2009 e 2011. (Professora 2 da escola B). 
A partir dessa fala é possível constatar que essa educadora não enxerga os resultados do IBEB com credibilidade e acaba até mesmo se surpreendendo com as notas desse índice. A coordenadora dessa escola confirma essa fala da professora, argumentando, ao se referir ao IDEB, o seguinte:

"O papel dele é avaliar a escola, mas assim, eles avaliam de forma superficial, né! Que tem coisas que podem ser melhor e que pode ser menos, mas só que é de forma superficial."

Já a equipe de professores entrevistados da instituição A expuseram um olhar um tanto diferenciado daquelas educadoras, isso é notável já fala da gestora pedagógica:

Ai (respirou fundo) o IDEB. O IDEB da escola é um problema, entendeu? que a dez anos a gente vem perdendo dois pontos, desde 2006 que a gente vem perdendo dois pontos a cada ano. (calou-se). (Coordenadora da escola A)

O exposto por essa coordenadora demonstra a aflição dela pelos índices até então alcançados, mas também elucida o fato de que o IDEB, apesar de ser uma política avaliativa aplicada desde 2006, ainda é pouco conhecido profundamente, e isso ficou claro também na fala das professoras dessa escola, quando foi indagado sobre o que elas conheciam sobre esse instrumento foi afirmado o seguinte:

Conheço, não profundamente, né! Mas conheço, eeee... concordo com ele (professora 1 da escola A).

[...] "É... eu na tinha conhecimento, até então, mas esse ano eu comecei a receber algumas orientações da própria escola, porque esse ano nós tivemos a Provinha Brasil (professora 2 escola A) ".

Essa educadora, em sua fala aqui apresentada, confundi a Prova Brasil, que compõe o índice, com a Provinha Brasil, que parte do interesse de avaliar alunos no nível da alfabetização. E aquela (professora 1) demonstrou um total desconhecimento do que de fato o IDEB representa, prova disso é que não quis continuar com a exposição de sua visão sobre esse indicador

\subsection{O TRABALHO PEDAGÓGICO DESSAS DUAS ESCOLAS MEDIANTE AO IDEB}

Toda ação pedagógica desenvolvida na educação escolar traduz uma concepção, de mundo e de educação, que para Saviani (2007) a concepção que fundamenta a lógica das políticas educacionais que compõe o IDEB é da Pedagogia dos resultados, que não considera os processos desenvolvidos nas instituições educacionais.

Nessa investigação a partir da observação e da entrevista foi possível levantar algumas ações pedagógicas desenvolvidas ou não pelas escolas pesquisadas a fim de se obter uma boa média na nota do IDEB. Neste sentido, apesar das estratégias tomadas pelas duas escolas, para na busca de um bom 
índice, foram divergentes, entre a escola que superou as expectativas do MEC e a que obteve uma nota baixa, é notável alguns impactos dentro dessas instituições, mesmo que sutis, a partir da implementação desse instrumento que aferi a qualidade educacional escolar.

Desse modo, pode-se obervar que a escola que manter um bom índice e superou as expectativas do MEC parte de um trabalho em cima dos descritores avaliados pelo IDEB:

Sim, a gente procura trabalhar em cima dos descritores, aqueles descritores que estão em falham, esse ano mesmo nós já tivemos o resultado da ANA, já saiu e a gente já viu o que precisa ser trabalhado. Então, as questões que a gente faz os simulados os alunos, os descritores que tem mais dificuldade a gente procura enfocar as atividades naquele descritor. (Coordenadora escola B).

A professora dessa escola confirma, afirmando o seguinte:

É os descritores, assim no dia a dia eu ainda tenho dificuldade em trabalhar com esses descritores, eles são trabalhados só no ano que se vai fazer a Prova Brasil, no ano da Prova Brasil, no dia a dia é mais difícil de trabalhar esses descritores, também são atividades mesmo que você tem que xerocar aí fica difícil.(Professora 2 da escola B).

É possível analisar que apesar da dificuldade em trabalhar em cima dos descritores pelo fato de que esses desconsideram que há no Brasil diversas realidades e níveis de aprendizagem, por isso a professora afirma que eles são trabalhados somente no ano de aplicação da Prova Brasil.

Já a escola A, que é a escola que não atingiu a meta prevista pelo MEC, trabalha de forma diferente, o que se nota é certa apatia com relação ao uso dessas habilidades e competências cobradas nessas avaliações, e isso foi notável quando foi indagando se a escola trabalhava em cima dos resultados do IDEB e como o trabalha era feito.

Fazendo exatamente, partindo sempre do princípio (fala com tom de riso), a cada ano que a gente recebe a gente apresenta pra os profissionais como a gente fez essa semana e cada um dar um ideia de como gostaria de trabalhar e a partir daí, né? O problema é que depois (risos). A discussão existe, a gente discute tudo pra o que cada uma vai fazer pra melhorar o índice, mas a cada ano a gente ver que essas discussões não tiveram muito sucesso. (Coordenadora escola A).

Entretanto, as professoras entrevistadas dessa escola deixam claro que a existência dessa única reunião para discutir o IDEB, foi muito limitada, não surtindo muito efeito, porque como está exposto na fala dessas docentes e pode ser percebido através da observação desse encontro, não houve uma análise do que de fato era um descritor, como construí-lo e quais descritores precisariam ser desenvolvidos na sala de aula.

Não (enfático), infelizmente a escola aqui ainda não trabalha em cima dos resultados, que deveria haver um reforço pra os alunos que ainda tem muitas dificuldades e isso não existe na escola. A escola trabalha apenas com a rotina normal do ano letivo e alguns assuntos que são 
dados na Prova Brasil, mas fora isso a escola não realiza nenhuma outra atividade. (Professora 2 escola A).

O exposto por essa professora confirma o que pode ser analisado nas observações, o fato de que ainda não há um trabalho nessa instituição em cima dos resultados da Prova Brasil que compõe o IDEB. Essa professora reforça a sua afirmação:

Como eu falei só foram duas reuniões, na primeira foi passado rápido, foi passado o material e ficou e ter novos momentos, novos planejamentos da gente buscar conhecimentos e até atividades pra melhorar o dia a dia na sala de aula... pra preparar o aluno pra Provinha Brasil, mas não houve continuidade como eu tinha falado. Em reuniões e até em material deixou um pouco vago, deixou um pouco a desejar esse acompanhamento. (Professora 2 da escola A).

Nas colocações da professora 2 ficou explícito o fato de que ainda não há uma compreensão sobre o papel do IDEB e que como ele é configurado, pois nessa fala como também em tantas outras aborda a Prova Brasil como Provinha Brasil que é uma Prova que está direcionada a avaliar os alunos da alfabetização.

A apatia dessa escola demonstra o fato de que a implementação de uma política pública ou programas não se dá de forma direta, com a reprodução total do que foi planejado e isso se deve ao fato de que há uma distância entre a dinâmica das instituições que recebem a política e o que foi planejado para essa política, "sábio e necessário admitir que a implementação modifica as políticas públicas". (ARRETCHE, 2002, p.2, grifo da autora).

Cabe analisar, que a partir da observação, da única reunião pedagógica, em torno do IDEB, foi possível constatar que a estratégia desenvolvida por essa instituição se deu a partir da orientação de que as professoras deveriam focar em suas práticas nas disciplinas de Língua Portuguesa e Matemática. Esse fato foi enfaticamente explícito na fala da coordenadora Pedagógica que elucidou o seguinte na discussão com as docentes: "Foquem o trabalho em Língua Portuguesa e Matemática e as outras disciplinas vocês fazem trabalhinhos para casa", apesar de que na entrevista ela afirma o contrário:

Em São Paulo a lei foi mudada, não aqui a matriz curricular da gente continua a mesma, mas em São Paulo só se trabalha Português e Matemática do $1^{\circ}$ ao $3^{\circ}$ ano. Então eu gostaria de implantar aqui, mas não dar porque não é o correto porque tudo acaba indo estilo denuncia pra coordenadoria, mas seria o ideal você trabalhar só os primeiros anos...embora você não deixa de fazer um seminário com o aluno, o professor pode continuar meia hora, discutindo um assunto de Ciências de Religião ou de História ou de Geografia, mas focasse mais nessas duas disciplinas que são muito cobradas

É notório que devido ao fato de que essas avaliações que medem o IDEB considerarem apenas as disciplinas de Língua Portuguesa e Matemática, a gestão pedagógica das escolas se sente 
pressionadas reduzirem o trabalho pedagógico escolas nessas duas áreas de conhecimento, desconsiderando, assim, as demais.

Devido às exigências feitas na reunião, as professoras foram enfáticas em afirmar, que apesar do fato de que na escola ainda não há um trabalho mais intensivo em torno dos descritores dessas disciplinas aferidos pela Prova Brasil, há na escola uma priorização das disciplinas avaliadas pelo IDEB, como se nota no exposto da professora abaixo:

Foco, e a outras eu saio, né, distribuindo, desde que dentre as outras prevaleça Língua Portuguesa e Matemática. Até nas outras disciplinas a gente trabalha a leitura, a interpretação de texto, a gente trabalha também a questão das datas, trazendo pra eles escalas, pra eles, medidas, então tudo... mesmo em Ciências e História a gente procura trabalhar Língua Portuguesa e Matemática.(professora 2 da escola A).

Há uma desconsideração as áreas de conhecimento, pois até mesmo quando se trabalha as outras disciplinas as professoras não consideram os objetivos específicos dos demais campos de conhecimento, privilegiando apenas Língua Portuguesa e Matemática e esse fato pode ser notado até mesmo na observação em sala quando foi aplicado alguns textos de História e Geografia que era enfatizado somente a interpretação de texto.

\section{CONSIDERAÇÕES FINAIS}

De fato é possível considerar a partir dos dados e das discussões aqui levantadas, que o IDEB como parte como uma política estratégica de um Estado mínimo e ao mesmo tempo interventor, se configura como um possível modelo de práticas pedagógicas na formação de competências e habilidades requeridas na atualidade por ser um instrumento de verificação dos resultados escolares para aferir a qualidade dessas instituições e que devido a isso pressionam os educadores a buscarem bom resultados a todo custo, desconsiderando até mesmo as especificidades locais presentes.

De forma sintética, nessa pesquisa, constatou-se, que apesar das medidas tomadas pelas escolas a fim de obter uma boa média no IDEB serem diferentes, essas instituições tem tomado como modelo referencial para a prática pedagógica esse indicador, seja no trabalho com descritores ou na priorização das disciplinas consideradas na composição desse índice. 


\section{REFERÊNCIAS}

AFONSO, Almerindo J. Reforma Do Estado E Políticas Educacionais: entre a crise do estado- nação e a emergência da regulação supranacional. In: Educação \& Sociedade, Campinas, ano XXII, n. 75, Agosto/2001.

ALMEIDA, Claúdia Mara de; SOARES, Kátia Cristina Dambiski. Pedagogo escolar: as funções de supervisora e orientada. Curitiba: Ibpex, 2010

BRASIL. Ministério da Educação. PDE: Plano de Desenvolvimento da Educação: Prova Brasil: ensino fundamental: matrizes de referência, tópicos e descritores. Brasília: MEC, SEB; INEP, 2008.

. O Plano de Desenvolvimento da Educação: razões, princípios e

programas - PDE. Brasília, 2007.

BONAMINO, A.C.; SOUSA, S. Z. Três gerações de avaliação da educação básica no Brasil: Interfaces com o currículo da/na escola. Educação e Pesquisa, S.P., v.38, n.2, p. 373-388, abr./jun., 2007.

CAMINI. L. A gestão educacional e a relação entre os entes federados na Política do PDE/Plano de Metas Compromisso Todos pela Educação. Porto Alegre, Doutorado em Educação Universidade Federal do Rio Grande do Sul. Faculdade de Educação, Programa de Pós-Graduação em Educação. Porto Alegre, 2009.

FERREIRA, Eliza Bartolozzi. Políticas no Brasil em tempo da crise. IN: Ferreira, Eliza Bartolozzi; OLIVEIRA, Dalila Andrade. Crise da escola e políticas educativas. Belo Horizonte: Autêntica editora, 2009.

HENGEMUHLE, Adelar. Gestão de ensino e práticas pedagógicas. Petrópolis, RJ. Vozes, 2004. MACÊDO, Seandra Doreteu de. Gestão pedagógica em tempos de IDEB. Dissertação (Mestrado em Educação). Universidade Estadual do Ceará, Ceará, 2011. Disponível em: em: http://www.capes.gov.br/>. Acesso em: 08 ab. 2014.

NEVES, Lúcia Maria Wanderley. A sociedade civil com espaço estratégico de difusão da nova pedagogia da hegemonia. In: (org.). A nova pedagogia da hegemonia: estratégias do capital para educar o consenso. São Paulo: Xamã, 2005, p.85-125.

PECI, Alketa.Novo marco regulatório para o Brasil da Pós-privatização: O papel das Agências regulatórias em questão. Disponível em: http://www.anpad.org.br/admin/pdf/enanpad1999-ap13.pdf. Acesso em 03 de fev. de 2015

SACRISTÁN, J. Gimeno. O Currículo: uma reflexão sobre a prática. 3. Ed. Porto Alegre, ArtMed, 2000.

SANDER, Benno. Políticas públicas e gestão democrática da educação. Brasília:Liber Livro Editora, 2005.

SOUSA, Sandra Maria Lian Záquia de. Avaliação do rendimento escolar como instrumento de gestão educacional. In: OLIVEIRA, Dalila Andrade (org.). Gestão democrática da educação: desafios contemporâneos. 8. Ed. Petrópolis, RJ: Vozes, 2008. 